\title{
Aberrant DNA Methylation in Bladder Cancer among Saudi Arabia Population
}

\author{
Amna Shoaib Siddiqui ${ }^{1}$ Faizah A Alshehri ${ }^{2}$ Ahmed Yaqinuddin ${ }^{1}$ \\ ${ }^{1}$ Department of Anatomy and Genetics, College of Medicine, Al \\ Faisal University, Riyadh, Kingdom of Saudi Arabia \\ ${ }^{2}$ Office of Research and Innovation ORI, Alfaisal University, Riyadh, \\ Kingdom of Saudi Arabia

\begin{abstract}
Address for correspondence Ahmed Yaqinuddin, MBBS, PhD, FRCP (Edin), Department of Anatomy and Genetics, College of Medicine, Al Faisal University, P.O. Box 50927, Riyadh 11533, Kingdom of Saudi
\end{abstract} \\ Arabia (e-mail: ayaqinuddin@alfaisal.edu).
}

J Health Allied Sci NU 2021;11:164-169.

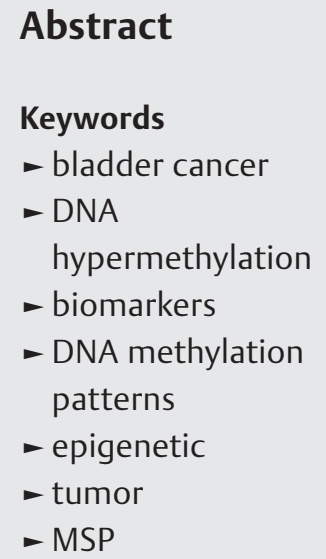

Tumor biomarkers developed based on the aberrant deoxyribonucleic acid (DNA) methylation patterns in bladder cancer (BC) hold great promise due to their stability, specificity, and known associations with the disease. No study has investigated DNA methylation patterns in BC patients from Saudi population. We analyzed DNA methylation levels of 48 tumor suppressor genes loci in 24 bladder tissues (19 BC and 5 control samples) using Human Tumour Suppressor Genes EpiTect Methyl II Complete PCR Array (Qiagen, Hilden, Germany). We identified significant difference in DNA hypermethylation levels at E2F1, ERBB2, HIC1, OPCML, SFN, SFRP1, SFRP2, SPARC, and TERT gene loci between controls and cancerous samples. SCGB3A1 was differentially methylated in nonmuscle invasive versus muscle invasive $B C$ samples. Results suggest that these aberrant DNA methylation patterns in $B C$ are disease and population specific and can be developed as distinct DNA methylation-based biomarkers for BC detection.

\section{Introduction}

Bladder cancer (BC) is the ninth most commonly occurring cancer among men in the Kingdom of Saudi Arabia (KSA), accounting for $4.0 \%$ incidence rate ${ }^{1}$ Excessive tobacco consumption, exposure to increased levels of toxic chemicals, petroleum products, and infection with Schistosoma haematobium reflects the strong association with the continuous rise of $\mathrm{BC}$ in this region. Transitional cell carcinoma (TCC) represents the most common type (90\%) of BC. Approximately, $80 \%$ of the new TCC of patients are nonmuscle invasive bladder cancer (NMIBC) and have good prognosis with more than $80 \%$ chance of 10 years survival rate; however, majority of the treated cases recur and progress to muscle invasive (MIBC). The most challenging aspect of $\mathrm{BC}$ is early diagnosis. Currently, periodic cystoscopy along with urine cytology is the essential prognostic and diagnostic tool for $\mathrm{BC}$ despite the fact that cystoscopy is invasive and has variable sensitivity. ${ }^{2}$ Radiology imaging including utilization of computed tomography scan and/or magnetic resonance imaging scan are additional means of monitoring the progress and nonprogress of new TCC of the urinary bladder. Such limitations have increased interest in identifying nucleic acid-based biomarkers. CpG island hypermethylation has been reported as a strong indicator of bladder carcinogenesis. ${ }^{3-6}$ Currently, aberrant modification of deoxyribonucleic acid (DNA) methylation patterns of tumor suppressor genes is of particular interest. ${ }^{3-6}$ These aberrant DNA methylation patterns can be detected in blood, urine, or serum of the cancer patient as cfDNA. ${ }^{2}$ Although these alterations are dynamic and respond to environmental influences ${ }^{7}$ and have been studied worldwide, ${ }^{8}$ to date no study has profiled similar alterations in Saudi population of BC patients. Therefore, in this study, we analyzed the DNA methylation patterns in BC, using a panel of 48 candidate genes loci. published online May 11, 2021
DOI https://doi.org/

$10.1055 / \mathrm{s}-0041-1726685$

ISSN 2582-4287 (c) 2021. Nitte (Deemed to be University).

This is an open access article published by Thieme under the terms of the Creative Commons Attribution-NonDerivative-NonCommercial-License, permitting copying and reproduction so long as the original work is given appropriate credit. Contents may not be used for commercial purposes, or adapted, remixed, transformed or built upon. (https://creativecommons.org/licenses/by-nc-nd/4.0/).

Thieme Medical and Scientific Publishers Pvt. Ltd. A-12, 2nd Floor, Sector 2, Noida-201301 UP, India 


\section{Materials and Methods}

\section{Sample Collection}

This study was performed in the Urology Clinic, at tertiary care hospital in KSA after the approval from the Ethics Committee. Informed Consent was taken from all the participants of the study. Nineteen fresh samples of BC tissue from the patients were collected who underwent cystoscopy. As control, five corresponding normal appearing tissue samples from the same patients, adjacent to tumor, were also obtained. Patients were selected consecutively based on tissue availability with no age, gender, or ethnic restrictions. Exclusion criteria were patients with cystitis and tumor other than the BC.

Tumor tissue samples were obtained immediately after cystoscopy and were frozen as part of the routine protocol. All samples were stored at $-80 \circ \mathrm{C}$. The presence and extent of tumor were evaluated by hematoxylin and eosin stains, to ensure at least $70 \%$ of tumor in the tumor samples. Tumor classification (World Health Organization [WHO]) and staging (tumor, nodes, metastasis, [TNM]) were routinely assessed for all tumor cases in formalin-fixed paraffin-embedded tissue. Detailed demographic and clinicopathologic parameters for all the samples are listed in - Table $\mathbf{1}$.

\section{DNA Extraction}

Genomic DNA was isolated using the Gentra Puregene Tissue kit (Qiagen). Briefly, DNA was digested overnight with proteinase $\mathrm{K}(1.5 \mu \mathrm{L})$ in the presence of $10 \%$ sodium dodecyl sulfate at $55^{\circ} \mathrm{C}$, precipitated with isopropanol and $70 \%$ ethanol.

\section{Selection of Genes}

After a literature examination, 48 genes were selected for the evaluation of methylation abnormalities in BC. All genes analyzed in this study were previously reported as targets for epigenetic silencing in different human cancers ${ }^{9-12)}$ that could also contribute to the tumorigenesis process in $\mathrm{BC}^{3}$.

\section{EpiTect Methyl II qPCR array}

The EpiTect Methyl II PCR Array (Qiagen) was used as a screening method to evaluate the promoter methylation status at 48 tumor suppressor genes in 24 samples. The assays were performed using the EpiTect Methyl II DNA Restriction Kit (Qiagen) according to the manufacturer's instructions. Briefly, $4 \mu \mathrm{g}$ of genomic DNA was incubated overnight at $37 \circ \mathrm{C}$ with a DNA methylation-sensitive restriction enzyme (Ms), which digests unmethylated DNA, with a DNA methylation-dependent restriction enzyme (Md) that digests methylated DNA, with both enzymes(Msd), and without enzyme added/"mock"(Mo) in four separate tubes. Following digestion, the remaining DNA in each "individual enzyme reaction was quantified by real-time polymerase chain reaction (PCR) using predesigned primers to the promoter region of the selected 48 genes. DNA amplification was carried on a 7,000 Sequence Detection System (Applied Biosystems, Foster City, California, United States), at $95 \circ \mathrm{C}$ for 10 minutes followed by 40 cycles of $97 \circ \mathrm{C}$ for 15 seconds and $72 \circ \mathrm{C}$ for 1 minute. PCR product was marked
Table 1 Summary of clinical pathological data of tumor and normal control samples

\begin{tabular}{|c|c|c|}
\hline & $\begin{array}{l}\text { Cancer cases } \\
(n=19)\end{array}$ & $\begin{array}{l}\text { Control } \\
(n=5)\end{array}$ \\
\hline \multicolumn{3}{|l|}{ Age } \\
\hline Median & 60 & 60 \\
\hline Range & $30-85$ & $42-72$ \\
\hline \multicolumn{3}{|l|}{ Gender } \\
\hline Male & $14(74 \%)$ & $4(80 \%)$ \\
\hline Female & $5(26 \%)$ & $1(20 \%)$ \\
\hline \multicolumn{3}{|l|}{ Extent } \\
\hline Invasive (MIBC) & $8(42 \%)$ & \\
\hline $\begin{array}{l}\text { Noninvasive } \\
\text { (NMIBC) }\end{array}$ & 11 (58\%) & \\
\hline \multicolumn{3}{|l|}{ Pathological stage } \\
\hline Stage CIS & $1(5.2 \%)$ & \\
\hline Stage Ta & $10(52.6 \%)$ & \\
\hline Stage T1 & 0 & \\
\hline Stage T2 & $7(36.8 \%)$ & \\
\hline Stage T3 & 0 & \\
\hline Stage T4 & $1(5.2 \%)$ & \\
\hline \multicolumn{3}{|l|}{ Grade } \\
\hline High grade & $12(63 \%)$ & \\
\hline Low grade & 7 (37\%) & \\
\hline \multicolumn{3}{|l|}{ Relapse } \\
\hline Primary & $6(31.5 \%)$ & \\
\hline Recurrence & $13(68.5 \%)$ & \\
\hline
\end{tabular}

Abbreviations: MIBC, muscle invasive bladder cancer; NMIBC, nonmuscle invasive bladder cancer;

with SYBR Green and Ct values were obtained. The analysis was performed using a SABiosciences Excel-Based Data Analysis Template, and the percentage of hypermethylated DNA was obtained by comparing the amount of DNA in each digest with that of a mock digest, representing the fraction of input DNA containing at least two methylated $\mathrm{CpG}$ sites in the targeted gene region. Statistically significant associations for promoter methylation for each gene were assessed using Student's $t$-test with a $5 \%$ significance level.

\section{Results and Discussion}

In our methylation-specific polymerase chain reaction analysis, significant difference in DNA hypermethylation frequencies was observed at nine genes (E2F1, ERBB2, HIC1, OPCML, SFN, SFRP1, SFRP2, SPARC, and TERT) in cancerous compared with normal tissue samples in regard to set of tumor existence (-Table 2). Only SFN gene showed significantly lower hypermethylation with $p$-value $=0.0011$ in comparison to 
Table 2 Genes showing statistically significant evidence of differential methylation among noninvasive, invasive cancer and controls

\begin{tabular}{|c|c|c|c|c|c|c|}
\hline \multirow[t]{2}{*}{ Genes } & \multicolumn{3}{|c|}{ Cancer versus controls } & \multicolumn{3}{|c|}{ Invasive versus noninvasive } \\
\hline & $\begin{array}{l}\text { Cancer } \\
(\text { mean } \pm S D)\end{array}$ & $\begin{array}{l}\text { Controls } \\
\text { (mean } \pm \text { SD) }\end{array}$ & $p$-Value & $\begin{array}{l}\text { Invasive } \\
(\text { mean } \pm \text { SD) }\end{array}$ & $\begin{array}{l}\text { Noninvasive } \\
\text { (mean } \pm \text { SD) }\end{array}$ & $p$-Value \\
\hline E2F1 & $17.71 \pm 16.75$ & $3.15 \pm 3.5$ & $0.002^{\mathrm{a}}$ & $16.09 \pm 14.48$ & $17.5 \pm 19.62$ & \\
\hline EGFR & $62.81 \pm 3.85$ & $62.28 \pm 6.14$ & & $63.88 \pm 4.48$ & $61.3 \pm 2.73$ & \\
\hline ERBB2 & $59.6 \pm 2.09$ & $56.06 \pm 1.25$ & $0.0006^{\mathrm{a}}$ & $60.29 \pm 2.13$ & $58.85 \pm 2.02$ & \\
\hline FAS & $64.18 \pm 3.16$ & $56.67 \pm 14.51$ & & $65.1 \pm 3.06$ & $63.24 \pm 3.33$ & \\
\hline FOS & $60.59 \pm 2.59$ & $59.69 \pm 2.21$ & & $59.87 \pm 3.21$ & $60.99 \pm 1.77$ & \\
\hline HIC1 & $79.84 \pm 11.43$ & $67.7 \pm 2.87$ & $0.0004^{a}$ & $77.27 \pm 11.38$ & $82.74 \pm 12.11$ & \\
\hline HOXA1 & $60.13 \pm 3.36$ & $59.33 \pm 3.69$ & & $60.55 \pm 3.33$ & $59.29 \pm 3.39$ & \\
\hline HRAS & $63.22 \pm 8.55$ & $61.98 \pm 1.72$ & & $65.43 \pm 3.9$ & $60.46 \pm 11.51$ & \\
\hline IGF2R & $64.08 \pm 3.71$ & $62.1 \pm 1.46$ & & $63.58 \pm 3.91$ & $64.56 \pm 3.9$ & \\
\hline ING1 & $61.61 \pm 7.01$ & $65.06 \pm 2.67$ & & $63.25 \pm 2.84$ & $59.78 \pm 9.77$ & \\
\hline JUN & $58.41 \pm 6.66$ & $58.5 \pm 1.73$ & & $59.43 \pm 3.56$ & $57.09 \pm 9.11$ & \\
\hline LOX & $60.53 \pm 3.5$ & $63.07 \pm 5.45$ & & $60.56 \pm 2.73$ & $61.13 \pm 3.97$ & \\
\hline MDM2 & $62.55 \pm 3.08$ & $56.26 \pm 13.47$ & & $61.6 \pm 2.46$ & $63.5 \pm 3.65$ & \\
\hline MEN1 & $60.9 \pm 3.74$ & $60.54 \pm 3.11$ & & $60.43 \pm 3.94$ & $60.82 \pm 3.55$ & \\
\hline MYC & $62.7 \pm 2.86$ & $63.07 \pm 1.79$ & & $62.07 \pm 2.46$ & $63.28 \pm 3.38$ & \\
\hline MYCN & $62.34 \pm 13.54$ & $60.16 \pm 5.73$ & & $64.26 \pm 7.37$ & $60.54 \pm 18.71$ & \\
\hline NF1 & $58.7 \pm 6.82$ & $59.28 \pm 3.45$ & & $57.13 \pm 9.3$ & $59.37 \pm 2.55$ & \\
\hline NF2 & $55.12 \pm 9.45$ & $56.96 \pm 1.67$ & & $57.48 \pm 3.54$ & $52 \pm 12.86$ & \\
\hline NFKB1 & $63.56 \pm 3.89$ & $62.4 \pm 2.8$ & & $62.91 \pm 3.42$ & $63.83 \pm 4.52$ & \\
\hline NME1 & $60.34 \pm 2.27$ & $59.35 \pm 1.03$ & & $60.36 \pm 1.34$ & $60.17 \pm 3.09$ & \\
\hline OPCML & $74.62 \pm 10.36$ & $59.31 \pm 14.04$ & $0.0119^{a}$ & $77.35 \pm 8.5$ & $73.07 \pm 12.01$ & \\
\hline PRDM2 & $63.71 \pm 3.44$ & $62.79 \pm 1.4$ & & $63.81 \pm 3.45$ & $63.64 \pm 3.83$ & \\
\hline PTCH1 & $60.56 \pm 7.89$ & $56.39 \pm 12.84$ & & $62.88 \pm 3.3$ & $57.88 \pm 10.667$ & \\
\hline PTGS2 & $61.94 \pm 3.49$ & $62.58 \pm 2.83$ & & $61.82 \pm 2.68$ & $62.04 \pm 4.49$ & \\
\hline PYCARD & $29.25 \pm 17.76$ & $33.34 \pm 23.44$ & & $30.78 \pm 16.68$ & $28.12 \pm 20.63$ & \\
\hline RB1 & $60.41 \pm 3.18$ & $57.72 \pm 16.79$ & & $60.73 \pm 3.38$ & $59.38 \pm 2.22$ & \\
\hline RET & $64.93 \pm 8.45$ & $60.28 \pm 3.33$ & & $68.57 \pm 11.36$ & $61.45 \pm 1.71$ & \\
\hline SCGB3A1 & $73.4 \pm 6.97$ & $73.39 \pm 3.72$ & & $77.06 \pm 8.03$ & $69.95 \pm 4.01$ & 0.0355 \\
\hline SFN & $74.22 \pm 8.97$ & $93.09 \pm 7.05$ & $0.0011^{\mathrm{a}}$ & $77.32 \pm 9.47$ & $71.31 \pm 8.41$ & \\
\hline SFRP1 & $71.51 \pm 6.76$ & $64.36 \pm 3.43$ & $0.0059^{\mathrm{a}}$ & $74.34 \pm 6.59$ & $69.29 \pm 6.42$ & \\
\hline SFRP2 & $77.29 \pm 12.41$ & $64.83 \pm 3.47$ & $0.0009^{a}$ & $80.02 \pm 11.48$ & $75.52 \pm 13.91$ & \\
\hline SH3PXD2A & $60.3 \pm 3.04$ & $60.73 \pm 3.01$ & & $60.65 \pm 1.72$ & $59.78 \pm 4.13$ & \\
\hline SLC5A8 & $80.38 \pm 11.57$ & $72.73 \pm 8.33$ & & $83.45 \pm 10.67$ & $78.66 \pm 12.44$ & \\
\hline SMAD4 & $61.43 \pm 3.28$ & $62.01 \pm 1.44$ & & $60.95 \pm 2.65$ & $62.14 \pm 3.97$ & \\
\hline SMARCB1 & $56.57 \pm 7.85$ & $60.73 \pm 2.6$ & & $54.81 \pm 10.98$ & $57.97 \pm 3.34$ & \\
\hline SPARC & $51.24 \pm 20.89$ & $27.05 \pm 19.04$ & 0.0435 & $58.32 \pm 17.79$ & $48.44 \pm 0.36$ & \\
\hline TERT & $77.68 \pm 6.95$ & $70.22 \pm 4.31$ & $0.0134^{a}$ & $79.45 \pm 5.03$ & $76.64 \pm 8.57$ & \\
\hline
\end{tabular}


Table 2 (Continued)

\begin{tabular}{|c|c|c|c|c|c|c|}
\hline \multirow[t]{2}{*}{ Genes } & \multicolumn{3}{|c|}{ Cancer versus controls } & \multicolumn{3}{|c|}{ Invasive versus noninvasive } \\
\hline & $\begin{array}{l}\text { Cancer } \\
(\text { mean } \pm S D)\end{array}$ & $\begin{array}{l}\text { Controls } \\
\text { (mean } \pm \text { SD) }\end{array}$ & $p$-Value & $\begin{array}{l}\text { Invasive } \\
\text { (mean } \pm S D)\end{array}$ & $\begin{array}{l}\text { Noninvasive } \\
\text { (mean } \pm \text { SD) }\end{array}$ & $p$-Value \\
\hline TGFB1 & $60.03 \pm 8.36$ & $62.91 \pm 1.83$ & & $61.26 \pm 3.95$ & $58.15 \pm 11.49$ & \\
\hline TGFBR2 & $64.83 \pm 2.91$ & $65.03 \pm 3.21$ & & $65.48 \pm 2.17$ & $63.63 \pm 3.03$ & \\
\hline THBS1 & $61.9 \pm 3.54$ & $62.28 \pm 2.66$ & & $62.75 \pm 2.89$ & $60.93 \pm 4.23$ & \\
\hline TP53 & $59.38 \pm 6.82$ & $60.97 \pm 2.01$ & & $61.92 \pm 3.53$ & $56.15 \pm 8.26$ & \\
\hline TSC1 & $57.56 \pm 7.78$ & $59.38 \pm 2.97$ & & $59.26 \pm 4.21$ & $55.17 \pm 10.2$ & \\
\hline TSC2 & $61.82 \pm 2.9$ & $58.28 \pm 14.65$ & & $62.01 \pm 2.66$ & $61.26 \pm 3.15$ & \\
\hline VEGFA & $62.06 \pm 3.16$ & $61.53 \pm 1.93$ & & $62.16 \pm 2.78$ & $61.43 \pm 3.38$ & \\
\hline WT1 & $72.55 \pm 9.46$ & $68.17 \pm 2.89$ & & $75.14 \pm 10.15$ & $70.12 \pm 9.17$ & \\
\hline WWOX & $58.43 \pm 7.86$ & $60.29 \pm 3.23$ & & $59.67 \pm 2.57$ & $56.69 \pm 11.16$ & \\
\hline XRCC1 & $61.53 \pm 3.55$ & $61.9 \pm 3.9$ & & $61.36 \pm 1.98$ & $61.51 \pm 4.9$ & \\
\hline ZMYND10 & $63.05 \pm 7.54$ & $64.49 \pm 2.1$ & & $64.33 \pm 4.45$ & $61.43 \pm 10.1$ & \\
\hline
\end{tabular}

Abbreviation: SD, standard deviation.

Significant $p$-value $=<0.05$.

a Highly significant.

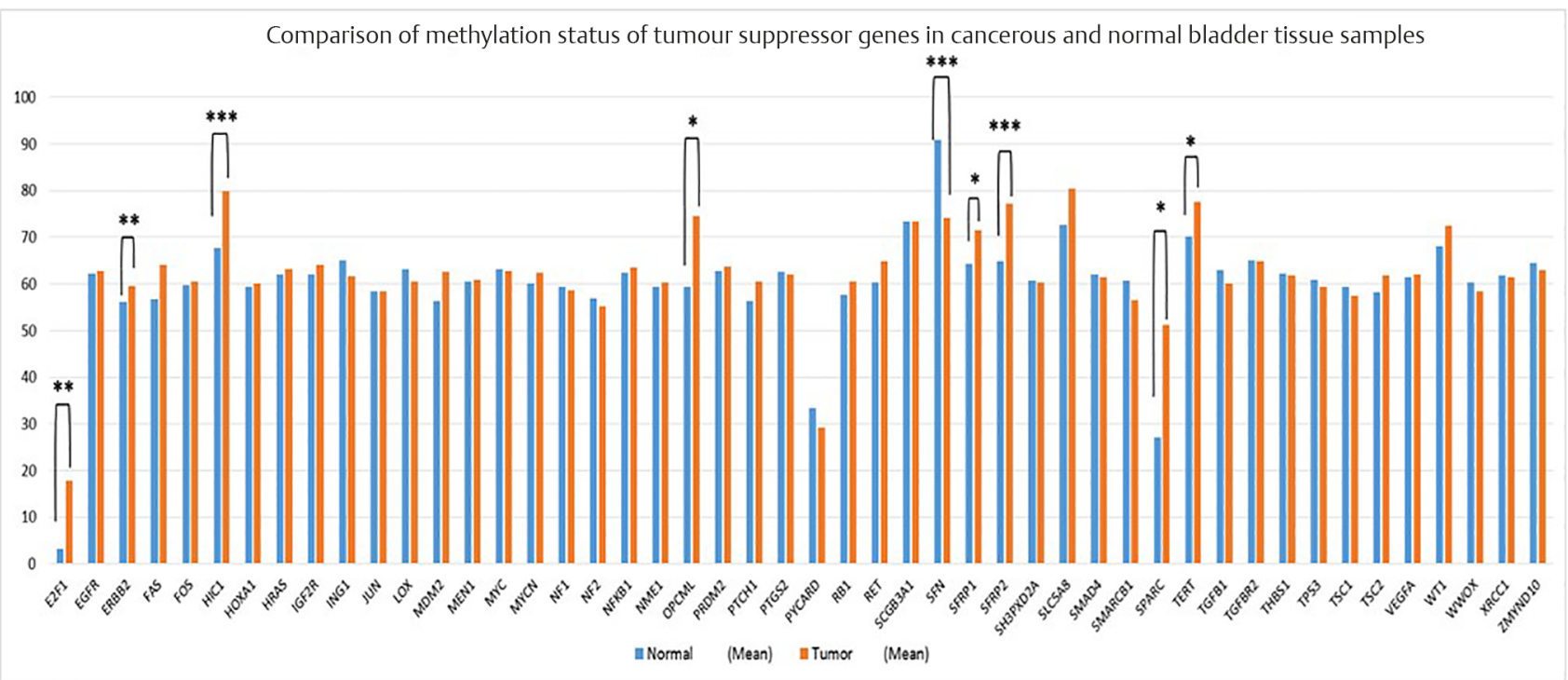

Fig. 1 The histogram showing deoxyribonucleic acid methylation profile between normal and cancerous bladder tissue among Saudi population. ${ }^{*}$ and ${ }^{* *}$ denotes $p$-value $<0.05$ and 0.01 , respectively (Student's $t$-test).

other eight genes that shows increase hypermethylation frequency in bladder cancerous tissue samples with most significant HIC1, SFRP2, and ERBB2 genes (- Fig. 1). Silencing of most of these highly significant genes, due to methylation of their promoter regions, have been reported in multiple human cancer types. However, some of these genes have not been investigated, thus far, in BC. This suggests that the panel of candidate genes selected is appropriate to detect aberrant methylation profiles in $\mathrm{BC}$ patients and can be considered specific for Saudi Arabian population. It was also observed that SCGB3A1 demonstrated the lower hypermethylation $(p=0.0355)$ in NMIBC versus MIBC samples. In contrast, no significant difference in DNA methylation levels at any gene promoter was found to be associated with tumor grade. Evidence suggests that these altered DNA methylation patterns are dynamic and respond to environmental influences. To our knowledge, this is the first study that has analyzed the methylation patterns in BC, using a panel of 48 candidate genes loci in 19 BC patients from Saudi Arabian population.

Limited studies in the past had observed the methylation patterns of SFN, HIC1, OPCML tumor suppressor genes in relation to $\mathrm{BC} .{ }^{13-15}$ One reason could be related to the methodologies used in the past or the dynamic patterns of DNA methylation due to diverse environmental exposure. SFN (Stratifin) is a protein kinase coding gene associated mainly with breast and pancreatic carcinoma. Although Negraes et al 
have previously reported the hypermethylation of SFN gene in $\mathrm{BC},{ }^{16}$ but due to its indistinct hypermethylation pattern in both cancerous and control group, it was not considered favorable for biomarker for BC detection. Similarly, silencing of HIC1 gene due to methylation of their promoter regions has been reported in multiple human cancer types including $\mathrm{BC}^{17}$ but no significant results were reported in $\mathrm{BC}$ to date. In contrast, our study has revealed significant DNA hypermethylation of both SFN and HIC1 genes making them promising biomarkers for BC patients in Saudi Arabia. OPCML promoter hypermethylation in $\mathrm{BC}$ has previously been reported only by one study..$^{18}$ This study showed overall frequency of DNA methylation was $60 \%$ and methylation levels were significantly higher among BC patients when compared with normal mucosa ( $p=0.0001)$. Our study was consistent with these findings and has shown that the significant hypermethylation of OPCML has a potential role in BC. It has been reported that SCGB3A1 hypermethylation plays an important role in the carcinogenesis of several human malignancies including breast cancer. ${ }^{19}$ Our study showed significant decrease of DNA methylation levels of SCGB3A1 in patients with MIBC as compared with NMIBC. In this context, decrease in DNA methylation status of this putative tumor suppressor gene would require further observation so that it can be used specifically for the surveillance of invasive bladder tumors in future.

\section{Conclusion}

In conclusion, this is a pilot study and we have identified distinctive genes that show evidence of differential methylation between cancerous and normal tissue, noninvasive, and invasive cancer tissue specific for the Saudi Arabian population. Such DNA methylation-based biomarkers will later help us to develop biomarkers specifically for the Saudi Arabian population. However, larger studies on BC-associated changes in DNA methylation are required for better diagnosis and prediction of the disease.

\section{Study Limitations}

This is a pilot study to screen out potential DNA methylation markers that can used in future for detection and prognosis of $B C$ on a large representing sample size of Saudi population. As we were screening 48 tumor suppressors, we needed large quantity of good quality DNA ( $4 \mu \mathrm{g})$ from our biopsy samples to conduct our experiments, which was not available from small size of the normal bladder biopsies. This is the reason we had only five control samples taken from the adjacent normal tissues of the $\mathrm{BC}$ patients. However, we compared the methylation differentiation for 48 genes in three different groups which was quite extensive and conducted for the very first time in this part of the region. Interestingly, a good number of genes showed significant results as well. Therefore, we can utilize this information from this pilot study as the screening tool for selecting some significant genes and run the similar analysis for bigger sample size with a smaller number of highly significant genes.

\section{Note}

All samples were collected from consenting patients/relatives according to institutional guidelines of participating hospital. Ethical approval was obtained from the Office of Research (ORA) of the Hospital and prior to the initiation of the study.

\section{Conflict of Interest}

None declared.

\section{References}

1 El-Siddig AA, Albasri AM, Hussainy AS, Alhujaily AS. Urinary bladder cancer in adults: a histopathological experience from Madinah, Saudi Arabia. J Pak Med Assoc 2017;67(1):83-86

2 Oeyen E, Hoekx L, De Wachter S, Baldewijns M, Ameye F, Mertens I. Bladder cancer diagnosis and follow-up: The current status and possible role of extracellular vesicles. International Journal of Molecular Sciences. 2019;20(4):821

3 Gurung PMS, Barnett AR, Wilson JS, et al. Prognostic DNA methylation biomarkers in high-risk non-muscle-invasive bladder cancer: a systematic review to identify loci for prospective validation. Eur Urol Focus 2020;6(4):683-697

4 Larsen LK, Lind GE, Guldberg P, Dahl C. DNA-methylation-based detection of urological cancer in urine: overview of biomarkers and considerations on biomarker design, source of DNA, and detection technologies. Int J Mol Sci 2019;20(11):E2657

5 Martinez VG, Munera-Maravilla E, Bernardini A, et al. Epigenetics of bladder cancer: where biomarkers and therapeutic targets meet. Front Genet 2019;10:1125

6 Yu Y, Cao H, Zhang M, Shi F, Wang R, Liu X. Prognostic value of DNA methylation for bladder cancer. Clin Chim Acta 2018;484:207-212

7 Turner BM. Epigenetic responses to environmental change and their evolutionary implications. Philos Trans R Soc Lond B Biol Sci 2009;364(1534) :3403-3418

8 Carja O,MaclsaacJL, MahSM, etal.Worldwide patterns of human epigenetic variation. Nat Ecol Evol 2017;1(10):1577-1583

9 Callahan CL, Wang Y, Marian C, et al. DNA methylation and breast tumor clinicopathological features: The Western New York Exposures and Breast Cancer (WEB) study. Epigenetics 2016;11(9):643-652

10 Cree IA, Uttley L, Buckley Woods H, et al; UK Early Cancer Detection Consortium. The evidence base for circulating tumour DNA blood-based biomarkers for the early detection of cancer: a systematic mapping review. BMC Cancer 2017; 17(1):697

11 Garrigou S, Perkins G, Garlan F, et al. A study of hypermethylated circulating tumor DNA as a universal colorectal cancer biomarker. Clin Chem 2016;62(8):1129-1139

12 Constâncio V, Nunes SP, Henrique R, Jerónimo C. DNA methylation-based testing in liquid biopsies as detection and prognostic biomarkers for the four major cancer types. Cells 2020;9(3):624

13 Casadio V, Molinari C, Calistri D, et al. DNA methylation profiles as predictors of recurrence in non muscle invasive bladder cancer: an MS-MLPA approach. J Exp Clin Cancer Res 2013;32:94

14 Duarte-Pereira S, Paiva F, Costa VL, et al. Prognostic value of opioid binding protein/cell adhesion molecule-like promoter methylation in bladder carcinoma. Eur J Cancer 2011; 47(7):1106-1114 
15 Shan M, Zhang L, Liu Y, et al. DNA methylation profiles and their diagnostic utility in BC. Dis Markers 2019;2019:6328503

16 Negraes PD, Favaro FP, Camargo JL, et al. DNA methylation patterns in bladder cancer and washing cell sediments: a perspective for tumor recurrence detection. BMC Cancer 2008;8(1):238

17 Zhou X, Zhang P, Han H, Lei H, Zhang X. Hypermethylated in cancer 1 (HIC1) suppresses bladder cancer progression by targeting yes-associated protein (YAP) pathway. J Cell Biochem 2019;120(4):6471-6481
18 Duarte-Pereira S, Paiva F, Costa VL, et al. Prognostic value of opioid binding protein/cell adhesion molecule-like promoter methylation in bladder carcinoma. Eur J Cancer 2011;47(7):1106-1114

19 Dai D, Dong X-H, Cheng S-T, Zhu G, Guo X-L. Aberrant promoter methylation of HIN-1 gene may contribute to the pathogenesis of breast cancer: a meta-analysis. Tumour Biol 2014;35(8):8209-8216 